Original Research Paper

\title{
A Guideline of using Assistive Technologies and Educational Services for Students with Disabilities in Higher Education
}

\author{
${ }^{1}$ Theeratorn Lersilp and ${ }^{2}$ Suchitporn Lersilp \\ ${ }^{1}$ Department of Special Education, Faculty of Education, Chiang Mai Rajabhat University, Thailand \\ ${ }^{2}$ Department of Occupational Therapy, Faculty of Associated Medical Sciences, Chiang Mai University, Thailand
}

\author{
Article history \\ Received: 30-12-2016 \\ Revised: 23-04-2017 \\ Accepted: 28-04-2017 \\ Corresponding Author: \\ Theeratorn Lersilp \\ Department of Special \\ Education, Chiang Mai \\ Rajabhat University, Thailand \\ Email: theeratorn_ler@cmru.ac.th
}

\begin{abstract}
Assistive Technologies (AT) and Educational Services (ES) are important in the needs of students with disabilities in higher education and their availability should be studied to provide appropriate help for them. The objectives of this study were to explore the problems in using AT and ES for these students and develop a guideline from the perspective of key informants. Data were collected from a semi-structured interview process completed by two groups of key-informants such as 12 service providers and 26 undergraduate students with disabilities. The results found that the problems in providing and using AT and ES comprised seven components; budget; personnel; discomfort in borrowing and taking care of special equipment; centralized maintenance; varieties of special individual needs; effectiveness of AT; and an AT specialist. In addition, a guideline for using AT and ES for students with disabilities included support from the government and non-governmental organizations; a training and production manual for faculty staff; and central organization of AT. This result is useful information for related service providers in helping students with disabilities to access educational activities.
\end{abstract}

Keywords: Assistive Technology, Educational Service, Higher Education, Students with Disabilities, Guideline

\section{Introduction}

Although awareness exists on the needs of students with disabilities in higher education in Thailand, no universities have had special Educational Services (ES) for them. It was not until 2002 that the Thai Ministry of Education issued regulations for providing Assistive Technologies (AT), media and related services for students with disabilities (TME, 2008). These regulations encouraged equality and the opportunity for these students to access and receive AT and supporting services in higher education (Songjaren and Nongtong, 2004; Kachondham, 2010). The above mentioned regulations consist of a legal framework for the policy of national education towards students with disabilities, in the context of poor managerial mentality of decision makers in higher educational institutions. However, as there is a lack of research documentation on the use of AT and ES in Thailand, especially in educational settings, this research describes the recent adoption of AT for learning purposes.

When comparing the higher education system in Thailand to that in other countries, it was found that some countries see the concept of technology and service as a system that enables information gathering, access and communication, as initiated and processed by universities (Petty, 2012). In addition, some countries have an educational system that has evolved through learning solutions and adopting technology from a system (Anshari et al., 2017). In terms of the rights of students with disabilities, some countries state their right to education without discrimination and on the basis of equal opportunity. Each university is encouraged to use technologies and establish a system to support academic services for these students, such as Braille, sign language and other necessary equipment and tools (Al-Hmouz, 2014; Ari and Inan, 2010; Ismaili and Ibrahimi, 2016). Therefore, these countries have enabled students with disabilities to obtain the rights for education and technology by establishing a higher education system and policy of national education.

In the past, most people with disabilities in Thailand usually used low technology that was not complex and made from local knowledge, due to the high cost of high technology (Lersilp et al., 2016). In terms of AT and ES, students with disabilities were able to enhance their student life and participate in "real world" experiences. 
Although AT and ES provide better learning chances for these students, some AT does not achieve requirements related to usability or accessibility, or the necessity to apply flexibility and adaptability, which would help teachers and students to meet their teaching/learning needs, or mobility that would guarantee freedom of movement between different places inside and outside educational institutes (Fernandez-Lopez et al., 2013).

The meaning of AT and ES in this study is related to the rights of students with disabilities to obtain these devices for accessing their education. AT refers to a variety of devices, including services related to its use and help for persons with disabilities and special educational/rehabilitation needs to function better within the daily context and achieve a higher quality of life (Lancioni et al., 2012). There are 2 types of AT, including low-tech devices such as canes, walkers and magnifiers and high-tech ones such as electric wheelchairs, automatic doors and digital pens (WHO, 2009). At the same time, ES assists students with disabilities to improve their educational abilities throughout educational institutions. AT and ES are conceptualized into a universal design to provide access for all because they are not only produced for students with disabilities, but also adaptable or modifiable in various contexts for people in general.

Therefore, AT and ES are able to encourage students with disabilities to use their ability in accessing educational activities as students do in general.

Most students with disabilities in higher education are aware of their rights to obtain AT and ES for teaching and learning, but that awareness is not the only positive factor that encourages them to receive full services (OHEC, 2004). Many educational institutes advocate student rights and the acceptance and willingness of these students to practice and obtain expertise in order to gain full benefit and eliminate existing barriers also are important factors (Amatayakul, 1996; Lersilp et al., 2016). Thus, the use of AT and ES for teaching and learning was developed specifically to assist students with disabilities in overcoming barriers, accessing information, learning and participating in educational activities and reaching their potential for taking part in academic activities in the same way as students do in general (Forgrave, 2002; Rose, 2001; Ashton, 2002). Furthermore, Cooper and Boninger (2008) reported that not only modernization of technological and educational services, but also problematic trends in student development relate to new service delivery mechanisms, which change public policy and coordination among consumers, policymakers, manufacturers, researchers and service providers.

Therefore, it can be seen from above that many students with disabilities in Thailand understand their rights to obtain AT and ES for accessing educational activities, especially for those in a higher educational system, who have more opportunities to use these facilities than those out of it (Lersilp et al., 2013), as the Disability Support Service (DSS) in each higher educational institute coordinates and works with related organizations in order to support student rights. However, it was found that some students using AT and ES did not gain full benefit from their rights. Therefore, researchers raised the question of using AT and ES for undergraduate students with disabilities in higher education. Thus, the objectives of this paper were as follows:

- To explore problems in utilizing AT and ES for students with disabilities in higher educational institutes

- To develop a guideline for using AT and ES for students with disabilities in higher educational institutes

\section{Method}

This was a qualitative research conducted in six higher educational institutes located in upper northern Thailand. A total of 38 participants took part in two groups of key informants. The criterion for inclusion into the first group of 26 undergraduate students with disabilities, was enrollment into higher educational institutes during the 2015 academic year. The criteria for exclusion were students with severe problems of communication, which prevented their expression of ideas and opinions and their refusal to participate in this research. The second group of participants comprised 12 service providers and the inclusion criterion was experience in working with disabled students. The exclusion criterion was their refusal to participate in this research. The undergraduate students with disabilities comprised 7, 7, 7, 3 and 2 with visual, hearing, physical, autism and learning disability, respectively. The service providers comprised six directors of the DSS and six DSS staff.

The participants were informed about the purpose of the interviews and that the data would be used for academic research purposes. Each university gained permission to conduct data collection from a relevant service provider. Then, the consent form was given to all participants. Semi-structured interviews were adapted from the study of Lersilp et al. (2013), which comprised problems of providing and obtaining AT and ES and perspectives on how to use them accordingly with the characteristics and needs of students with disabilities. The semi-structured interview questions were as follows:

- What will the process be in your university for obtaining AT and/or ES for teaching and learning with regard to students with disabilities? Which organizations work with you? Do you have any problems or barriers during the above process?

- Do you have any problems or barriers in providing AT and/or ES for teaching and learning and if so what are they? 
- What kinds of AT and/or ES do you need more of for teaching and learning in students with disabilities in your university and what do you need them for?

- Which process do you consider effective for receiving AT and/or ES for students with disabilities in your university?

Qualitative data were analyzed by the thematic analysis method by extracting information from the students with disabilities and the service providers in order to identify implicit and explicit themes for synthesizing a guideline for using AT and ES in these students.

\section{Results}

\section{Providing and Obtaining AT and ES for Students with Disabilities}

Based on the findings, AT and ES were given to students with disabilities by service providers in higher educational institutions. Lists of AT were given to such students in six universities, including a reading aid, desktop computer, computer with Braille keyboard, screen reading program, zoom-tech program, ClosedCircuit Television (CCTV), Braille book, white cane, IC recorder, sign language dictionary and electronic lesson materials. In addition, lists of ES were given to these students, including transport, tutoring, note-taking, reading and writing, coordinating and sign language interpreting services, as well as examination adjustment.

\section{Analysis of Problems in Providing, Obtaining and Using AT and ES for Students with Disabilities}

These results came from the opinions of key informants, who opined seven problems with regard to providing, obtaining and using AT and ES for students with disabilities.

The first issue concerned policy, indicating that students with disabilities, who studied in inclusive/ mainstreaming schools or higher educational institutions, would have the right to receive AT and ES for teaching and learning, but these rights did not cover those who were studying in higher education. Thus, higher educational institutions were responsible for the costs involved, such as those for adjustment to architecture and the environment on campus, i.e., elevators, ramps, handrails, bathrooms, etc. In addition, the problems and barriers in providing AT and ES for teaching and learning was for all universities to receive them from non-governmental organizations, such as Saints for the Blind Foundation and National Association for the Deaf of Thailand, as set by the Office of the Higher Education Commission. However, the universities did not process this instruction, due to procurement regulations from the Procurement Department. Nevertheless, staff at the DSS had to process and submit a project to higher educational institutions in order to receive budgets and the needs of AT and ES for their students with disabilities had to be specified several years in advance. In consequence, universities could not process provision of any AT or ES for their students. It also affected the problem of delay in receiving these services, inadequacy in the needs of students and no cover for a variety of problems, especially in AT.

The second issue concerned the budget, which was a major problem relating to the acquisition of some AT and ES for teaching and learning. This was due to some items being obtained by requesting cooperation from relevant departments. With regards to hiring personnel as a sign language interpreter, note-taker, converter of text to Braille, an AT specialist, etc., ES had to rely on a budget for short-term employment. Also, the DSS was responsible for employing personnel with their own funds. It also was asked for a rating on available positions for acquiring part-time work in their universities, but it was not enough to suit the needs of the students.

The third issue concerned restrictions on personnel resulting from a partial budget that limited the supply of manpower. The personnel rate was available, but relatively small salary or compensation caused the work to be unattractive. This affected existing personnel by having them work in a variety of roles that made their efforts ineffective.

The fourth point concerned discomfort in borrowing and taking care of central equipment. Undergraduate students with disabilities did not want to have the responsibility of borrowing expensive equipment. This caused those who owned personal devices not to borrow equipment or AT provided by the universities. This added to the problem of delay in receiving AT and caused families with low socioeconomic status to be responsible for the expense, as they preferred to supply their own equipment instead of waiting for that provisioned from a higher educational institute. However, the problem was where to buy a specific technology or device.

The fifth issue concerned the variety of needs for students with different disabilities, which included access to AT and ES for teaching and learning. Some groups of undergraduate students with disabilities had more need to receive ES than AT, while others had more need for AT than ES.

The sixth point concerned problems and barriers in using AT for teaching and learning when performing existing technologies, which mostly involved outdated and defective computers. Each computer given to students must be shared with others.

Finally, the lack of AT experts is a problem that has deprived students the knowledge of this device. It has affected the understanding and skills of staff and students in the use of AT. Furthermore, when special equipment failed to work, staff and students did not know where to go for repairs or assistance. 
Analysis and Results on the Perspective of Students with Disabilities on a Guideline for using AT and ES that Accords with their Needs

Key informants pointed out three factors from the perspective of teaching and learning by using AT and ES for students with disabilities in higher education.

The first component concerned collaboration and support. A guideline for using AT and ES for teaching and learning should come from collaboration and support that involve all related organizations, including the government and non-governmental organizations and communities, such as the Office of the Higher Education Commission, educational institutions, foundations, mechanisms and networks of special education centers at the provincial and community levels, etc. However, the government organizations related to special education should be major ones that support and provide a system for AT and ES for teaching and learning. Organized collaboration should encourage undergraduate students with disabilities and their faculty of teachers and staff to participate in the process of decision-making, training and using AT as well as receiving ES. However, due to a limited budget, AT and ES staff and higher educational institutions should find a way to manage and help students with disabilities thoroughly and quickly by simply not expecting to receive full support from only the government.

The second point concerned a system for training and producing a manual for faculty staff. After AT and ES have been provided to undergraduate students with disabilities, faculty staff should participate in a learning course in order to receive knowledge and information about characterizing these students. They also should know about the importance of selection and teaching and learning through using AT and ES, as well as maintaining the former.

Finally, the central agency of AT for undergraduate students with disabilities should have an AT expert who is able to determine the properties of materials that accord with the problems and needs of the students. This agency could be a way of solving the delays in conveying technologies to students. It also includes receiving AT and ES for teaching and learning that do not meet the needs of these students. After the students have received AT and ES for teaching and learning, the agency should follow them up. Moreover, the role of a central agency should cover the survey system in a university by involving the type and number of AT and ES that would be needed before provision.

\section{A Guideline for using AT and ES for Students with Disabilities in Higher Education}

Analyzing the problems in providing and utilizing AT and ES for students with disabilities enabled a guideline for use in upper northern Thailand. It consisted of 6 related factors that led to 3 approaches, as seen in Fig. 1.

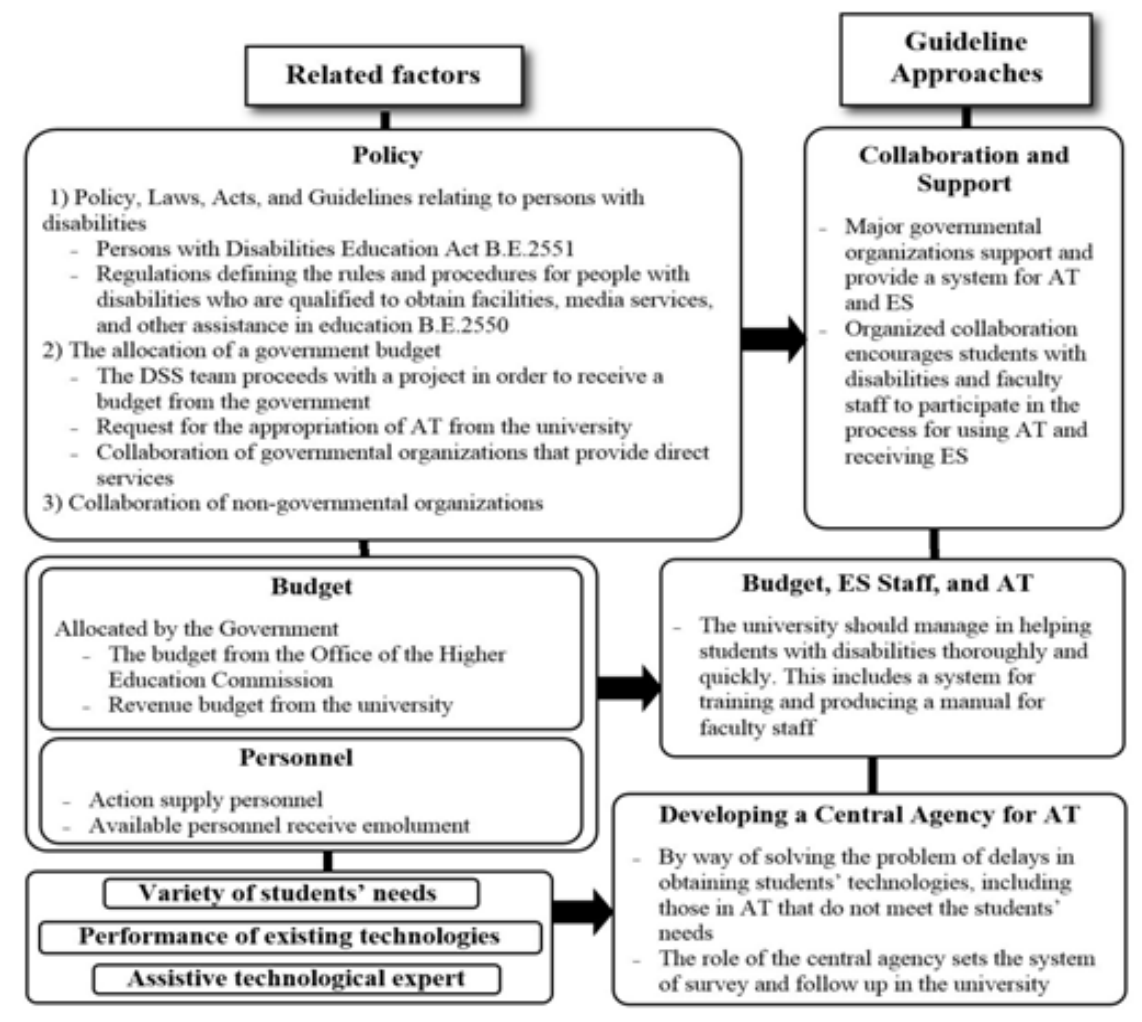

Fig. 1. Guideline for using AT and ES for students with disabilities in higher education 


\section{Discussion}

As the number of students with disabilities in higher education has increased in recent years, their academic needs, particularly for AT and ES, have to be explored in helping them to access learning activities. Several interesting findings from descriptive information and the interview were documented in this study. It was found initially that although students with disabilities could understand their right in accordance with educational regulations to receive AT and ES through the DSS center of their university (PDEA, 2009), some of them did not received all of these devices for teaching and learning. This discussion is in accordance with the studies of Barnes (2005), Butterwick and Benjamin (2006), who reported that educational regulation is not enough to affect a change and thus, a more complicated strategy of reviewing practices, procedures and active consultation for students with disabilities is required to work and study towards a fairer higher education.

The problems in providing and obtaining AT and ES for undergraduate students with disabilities were composed of seven issues: Policy; budget; personnel; discomfort in borrowing and taking care of centralized maintenance; variety of special individual needs; effectiveness of AT; and the AT specialist. This point of discussion related to the studies of Copley and Ziviani (2004), Phetmoo (1995), who reported that barriers in the use of AT in children with disabilities are: lack of support; improper training of personnel; insufficient funding; lack of comprehensive planning and the evaluation process; complexity of use; and time restriction in practical use. In addition, these problems were in line with a study by Al-Hmouz (2014), who found that students with disabilities were not satisfied with support provided by the Student Disability Office or designated resources in the university; e.g., assistive devices were not available for most of the students and teaching and administrative staff were not trained to deal with them. However, the responsibilities of specialists involved evaluating, counseling, training and utilizing AT.

From the problems mentioned above, three approaches were made in organizing a system for a guideline to provide and receive AT and ES. It included support from the government and non-governmental organizations; training and a production manual for faculty staff; and a central organization for AT. This guideline is consistent with a report by Prongsuntia (2015), who suggested that guidelines for education management in a university, based on the universal design concept, are as follows: (1) management should be aware of the importance of education for students with different disabilities by announcing a clear policy, system management and support services that contribute to all learners; (2) an education support team must also recognize the provision of services to on campus students with several kinds of disabilities; (3) all teachers must realize and accept their responsibility to teach different students, in every room and in every course; and (4) the DSS must act to assist and encourage students to access as much knowledge as possible. Also, these approaches in an organized system were supported by Ari and Inan (2010), who reported several related factors, including provision of trained staff for students with disabilities, knowledge and awareness of AT among these students and availability of AT from the administration of higher educational institutes.

A limitation of this study was its generalization, due to its location in "only upper northern Thailand", which might not apply to other areas of the country. Also, due to the educational system being unsuitable in Thailand for students with disabilities, many of them did not have the opportunity to study in university, especially those in rural areas. Therefore, the sample size was small in this study and the results obtained could not be generalized to other students around the country. There are current plans for future research to replicate this study with a larger sample size that would allow generalization across a wider area. This study also was limited by the fact that all participating students already had existing AT and ES. Furthermore, future researchers might take cultural factors into consideration as well.

\section{Conclusion and Recommendation}

In order that education is accessible to students with disabilities in higher education, various factors should be considered, including types of services provided, ways of using AT and support in the form of AT and ES availability for teaching and learning from university administration. Therefore, higher educational institutes should provide a suitable environment, software programs and AT and ES in order to enhance student success in the educational activities. The students reported that they enjoyed using AT and ES as educational and organizational devices, which allowed for a manageable divide between education and social activity. However, various problems were found in utilizing AT and ES in students with disabilities such as insufficient provision of these devices that would help these students to access information in the class; insufficient information for teachers about the needs of the students and how to utilize AT and ES; and insufficient training for teachers and service staff in helping students to access AT and ES effectively. Based on opinions of the participants, a guideline for providing and obtaining AT and ES for undergraduate students with disabilities consisted of six related factors: Policy; budget; personnel; variety of the students' needs; performance of existing technologies; and an AT expert, which led to three approaches including collaboration and 
support; budget; and developing a central agency for AT. However, some issues have been raised in this study regarding the guideline for provision of strategies in AT and ES for students with disabilities.

\section{Acknowledgement}

Authors are grateful to the anonymous reviewers and the editor for detailed comments. The usual disclaimer applies.

\section{Funding Information}

This research was supported by a grant from the National Research Council of Thailand (NRCT) to Chiang Mai Rajabhat University. Article publication was funded by the Division of Human Resource Management in Chiang Mai Rajabhat University.

\section{Author's Contributions}

Theeratorn Lersilp: Is the main author of this manuscript. He worked hard to make a final manuscript of the paper.

Suchitporn Lersilp: Is the promotor of Theeratorn, She contributed in reviewing the article in it critically for significant intellectual content.

\section{Ethics}

The authors declare no conflict of interest.

\section{References}

Al-Hmouz, 2014. Experiences of students with disabilities in a public university in Jordan. Int. J. Special Educ., 29: 25-32.

Amatayakul, P., 1996. Special education and modification of technology to children with disabilities. Seminar and Exhibition: Technology for Children with Disabilities. Bangkok Ratchasuda College, Mahidol University and National Electronics and Computer Technology Center.

Anshari, M., M.N. Almunawar, M. Shahrill, D.K. Wicaksono and M. Huda, 2017. Smartphones usage in the classrooms: Learning aid or interference? Educ. Inform. Technol., 22: 1-17. DOI: $10.1007 / \mathrm{s} 10639-017-9572-7$

Ari, I.A. and F.A. Inan, 2010. Assistive technologies for students with disabilities: A survey of access and use in Turkish universities. Turkish J. Educ. Technol., 9: 40-45.

Ashton, T.M., 2002. The assistive technology assessment: An instrument for team use. J. Special Educ. Technol., 17: 39-46.
Barnes, C., 2005. Independent living: Politics and policy in the United Kingdom: A social model account. J. Learn. Disability Stud., 36: 248-258.

Butterwick, S. and A. Benjamin, 2006. The road to employability through personal development: A critical analysis of the silences and ambiguities of the British Columbia (Canada) life skills curriculum. Int. J. Lifelong Educ., 25: 75-86.

Cooper, A.R. and M.L. Boninger, 2008. Trends and issues in wheelchair technologies. Assistive Technol., 20: 61-72.

Copley, J. and J. Ziviani, 2004. Barriers to the use of assistive technology for children with multiple disabilities. Occup. Ther. Int., 11: 229-243.

Fernandez-Lopez, A., M.J. Rodriguez-Fortiz, M.L. Rodriguez-Almendros and M.J. Martínez-Segura, 2013. Mobile learning technology based on iOS devices to support students with special education needs. Comput. Educ., 61: 77-90.

Forgrave, K.E., 2002. Assistive technology: Empowering students with disabilities. Clear. House, 75: 122-126.

Ismaili, J. and E.H.O. Ibrahimi, 2016. Mobile learning as alternative to assistive technology devices for special needs students. Educ Inform. Technol., 21: 1-17.

Kachondham, P., 2010. Disabled Students Services (DSS) in higher education in Thailand. NTUT Educ. Disabilities, 8: 29-34.

Lancioni, G.E., J.O. Sigafoos, M.F. Reilly and N.N. Singh, 2012. Assistive Technology: Interventions for Individuals with Severe/Profound and Multiple Disabilities. 1st Edn., Springer Science and Business Media, New York, ISBN-10: 146144229X, pp: 182.

Lersilp, S., S. Putthinoi and N. Chaimaha, 2016. Model of providing assistive technologies in special education schools. Global J. Health Sci., 8: 36-44.

Lersilp, S., S. Putthinoi and N. Chaimaha, 2013. The survey and development of an organized system to provide assistive technology for children with disabilities in special education schools. Faculty of Associated Medical Sciences, Chiang Mai University, Chiang Mai.

OHEC, 2004. Guidelines for the promotion and development of the welfare system for disabled students in higher education. Bangkok Office Higher Education Commission.

PDEA, 2009. Regulations of persons with disabilities education promotion B.E.2552. Bangkok Persons Disabilities Education Act.

Petty, R.E., 2012. Technology access in the workplace and higher education for persons with visual impairments: An examination of barriers and discussion of solutions. Independent Living Research Utilization TIRR: Houston, Texas. 
Phetmoo, K., 1995. A survey of needs and use of activity of daily living devices in elderly people. Occupational Therapy Department, Chiang Mai University, Chiang Mai.

Prongsuntia, S., 2015. Universal design for learning. Documentation Training Seminar.

Rose, D., 2001. Universal design for learning. J. Special Educ. Technol., 16: 64-67.
Songjaren, O. and T. Nongtong, 2004. The Development of Systematic Services for Ratchasuda College's Disability Support Services (DSS). J. Ratchasuda Coll. Res. Dev. Persons Disabilities, 3: 90-110.

TME, 2008. The Thai ministerial regulations for provision of assistive technology, media and services in people with disabilities B.E.2551. Bangkok Thai Ministry Education.

WHO, 2009. Assistive devices/technologies. World Health Organization. 